\title{
(2) OPEN ACCESS \\ Rare case of hepatocellular carcinoma metastasising to the pituitary and cavernous sinus causing panhypopituitarism and bilateral ophthalmoplegia
}

\author{
Jayachidambaram Ambalavanan $\odot,{ }^{1}$ Monica Peravali, ${ }^{2}$ David J Perry ${ }^{2}$
}

${ }^{1}$ Internal Medicine, MedStar Washington Hospital Center, Washington, DC, USA

${ }^{2}$ Hematology and Oncology, MedStar Washington Hospital Center, Washington, DC, USA

\section{Correspondence to}

Dr Jayachidambaram

Ambalavanan:

jayachidambaram.

ambalavanan@medstar.net

Accepted 24 September 2020

Check for updates

(c) BMJ Publishing Group Limited 2020. Re-use permitted under CC BY-NC. No commercial re-use. See rights and permissions. Published by BMJ.

To cite: Ambalavanan J, Peravali M, Perry DJ. BMJ Case Rep 2020;13:e236377. doi:10.1136/bcr-2020236377

\section{SUMMARY}

Pituitary metastases, especially from a primary hepatocellular carcinoma (HCC), are rare. Review of the literature revealed only few cases reporting pituitary metastases complicated by panhypopituitarism from HCC. Calvarial metastases from HCC are even more rare. Here, we present a unique case of primary $\mathrm{HCC}$ with metastases to both the calvarium and the pituitary causing panhypopituitarism and bilateral ophthalmoplegia, respectively. To our knowledge, this is the first reported case of two unique and rare complications from metastatic HCC.

\section{BACKGROUND}

Pituitary metastases are extremely rare. Sellar masses mostly comprise pituitary adenomas, while only $1 \%-2 \%$ of those masses are attributed to secondary metastases. ${ }^{12}$ When metastatic disease to the pituitary is present, it commonly arises from a primary breast or lung cancer. ${ }^{34}$

While 18\%-64\% of hepatocellular carcinomas (HCCs) metastasise, the most common site is usually the lung. Brain metastasis is infrequent, and isolated pituitary metastasis is even more rare. ${ }^{56}$

Symptoms from pituitary metastases are seen in $7 \%$ of cases, most commonly causing diabetes insipidus (DI) and headaches, signifying posterior pituitary involvement. Anterior pituitary dysfunction in the form of visual field defects and ophthalmoplegia is also a possible manifestation although less frequently seen. ${ }^{46}$

A thorough review of the literature reveals few cases of primary HCC, with metastasis to pituitary involving cavernous sinus, clivus and sphenoid sinus with resultant panhypopituitarism and cranial nerve palsies. ${ }^{7-13}$ However, it is extremely rare for all these manifestations to occur at the same time.

To our knowledge, we present the first case of primary HCC with metastases to both the calvarium (with sphenoid sinus involvement) and the pituitary causing bilateral ophthalmoplegia and panhypopituitarism, respectively.

\section{CASE PRESENTATION}

A 68-year-old man with chronic hepatitis B, HIV on highly active antiretroviral therapy and history of anal cancer in remission for 3 years initially presented with headache, generalised weakness, abdominal pain, nausea and vomiting. Physical examination was consistent with left eye ptosis with difficulty in opening his eye, while the rest of his neurological examination was unremarkable.

\section{INVESTIGATIONS}

Initial labs were significant for haemoglobin (128 $\mathrm{g} / \mathrm{L})$, white cell count $\left(8.5 \times 10^{9} / \mathrm{L}\right)$ and platelet count $\left(192 \times 10^{9} / \mathrm{L}\right)$. HIV labs were significant for absolute CD4 count (305 cells/ $\mu \mathrm{L}), \mathrm{CD} 4 / \mathrm{CD} 8$ ratio $(0.78)$ and HIV viral load $(<20)$, indicating an intact immune system. He also had a mild transaminitis (aspartate aminotransferase $=98$, alanine aminotransferase $=33$ ) and positive hepatitis B surface antigen and hepatitis B e-antigen. His hepatitis B viral DNA was 37603.

A sinus X-ray showed right lateral maxillary sinus thickening. Over the next few days, the patient developed abdominal pain with distension. CT of the abdomen and pelvis was done to rule out intestinal obstruction. It instead revealed multiple hypoattenuating poorly defined clustered hepatic lesions with mild surrounding hyperenhancement with invasion of the portal vein by tumour thrombus, which could have contributed to the abdominal pain. MRI of the abdomen (figure 1) was also done to better visualise the liver. It revealed a large $8.7 \times 8.5 \mathrm{~cm}^{2}$ lesion in the right posterior hepatic lobe. The differentials for the lesions at this point of time included HCC considering his hepatitis B status or atypical metastasis from anal cancer.

\section{TREATMENT}

Over the course of hospitalisation, the patient had alteration in mentation. His unilateral ptosis progressed rapidly to bilateral ptosis with complete ophthalmoplegia. CT of the head (figures 2 and 3) subsequently confirmed sphenoid sinus opacification with a mass in the pituitary invading into the cavernous sinus. Neurosurgery was consulted for brain mass with compressive symptoms, but surgical intervention was not possible due to the extent of tumour invasion around bilateral carotids. Hormonal studies were performed and revealed the following (table 1).

These were interpreted as showing panhypopituitarism. Once he started treatment with levothyroxine and dexamethasone, his mental status started improving.

Liver biopsy confirmed HCC (figures 4 and $5)$. Transsphenoidal biopsy of the pituitary lesion (figure 6) revealed concordant findings of HCC. He received palliative whole-brain radiation $(3000$ 


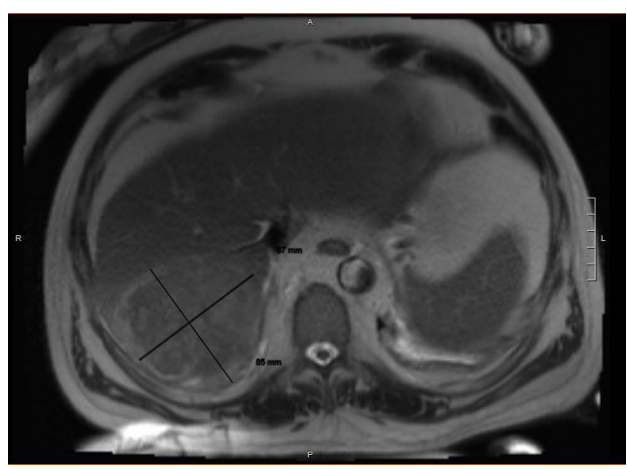

Figure 1 MRI of the liver: large area of heterogeneous signal abnormality involving the posterior right hepatic lobe/segment. ${ }^{7}$ The lesion measures approximately $8.7 \times 8.5 \mathrm{~cm}^{2}$ in size. It demonstrates heterogeneous mild $\mathrm{T} 2$ hyperintense signal and heterogeneous progressive enhancement. No washout was seen. Given other findings within the liver, this could relate to mixed-type hepatocellular carcinoma/cholangiocarcinoma.

cGy) over a period of 10 days, which unfortunately did not reverse his ophthalmoplegia.

\section{OUTCOME AND FOLLOW-UP}

$\mathrm{He}$ was subsequently discharged to a subacute rehabilitation facility with plans for outpatient follow-up with oncology. Unfortunately, he died 2 weeks after discharge.

\section{DISCUSSION}

Pituitary metastasis is an extremely rare and life-threatening complication. As discussed earlier, most of the pituitary tumours are primary adenomas, and only $1 \%-2 \%$ of all pituitary tumours can be attributed to metastasis. ${ }^{12}$

HCC metastasising to the pituitary also is very rare. A recent study ${ }^{5}$ evaluating the epidemiology of HCC showed that less than $18 \%$ were associated with metastasis; moreover, lung was

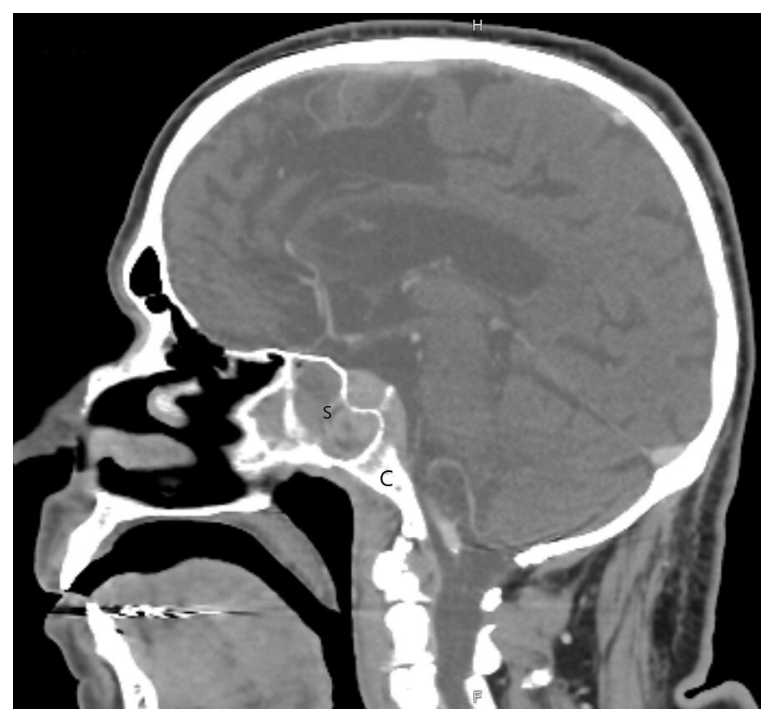

Figure 2 CT of the head, sagittal view: abnormal soft tissue extends posteriorly along the tentorium, with right being greater than left. There is destruction of bony landmarks including petrous apex, sphenoid bone and superior orbital fissure on the left. Optic canals are not involved at this time. The tumour extends through the foramen ovale below the skull base. C, clivus; S, sphenoid sinus.

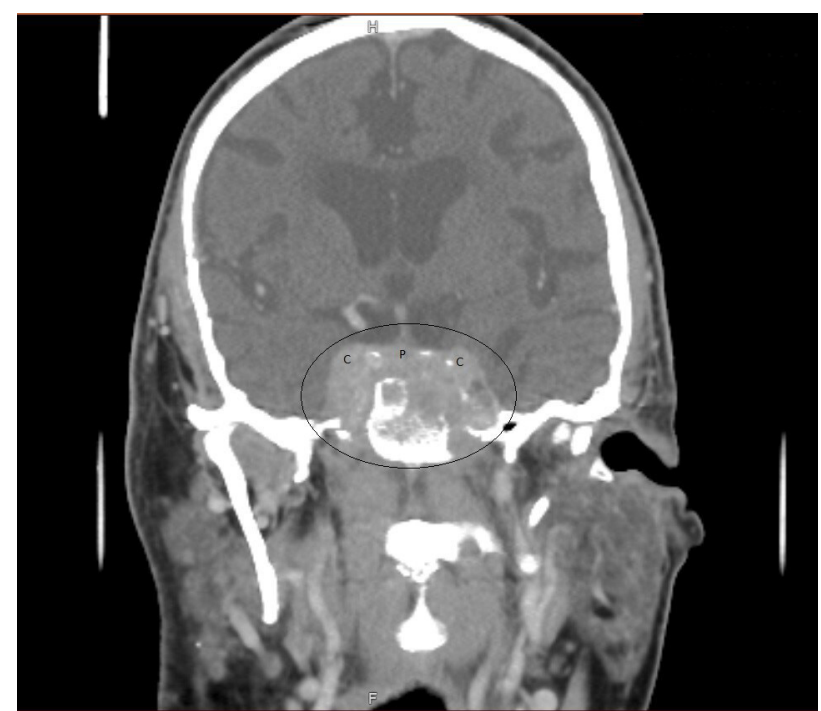

Figure $3 \mathrm{CT}$ of the head, coronal view: abnormal soft tissue involving the sellar, suprasellar and cavernous sinus regions bilaterally. It measures at least $44 \mathrm{~mm}$ in width by $27 \mathrm{~mm}$ in height by $44 \mathrm{~mm}$ in length. There are patchy areas of increased attenuation within the abnormal soft tissue. Enlarged region denotes hepatocellular carcinoma metastasis. $C$, cavernous sinus; $P$, pituitary.

the most frequent site for metastasis. Another study showed that this prevalence could be as high as $64 \% .{ }^{6}$ Despite a wide range of reported data on the incidence of metastatic HCC, only 11 cases of metastases to the pituitary have been reported in the current literature. ${ }^{714}$

Metastasis to the anterior pituitary is rarer than to the posterior pituitary. Less than $40 \%$ of all pituitary metastases are seen anteriorly likely due to several factors including differences in the blood supply of anterior pituitary (hypophyseal portal) and posterior pituitary (systemic circulation). ${ }^{15}$ Another possible mechanism could be the smaller size of the posterior pituitary, leading to earlier manifestations of symptoms even with low tumour burden. ${ }^{15}$

Posterior pituitary involvement causes DI and headache. The most common symptoms of anterior involvement include visual field deficits with cavernous sinus involvement, ophthalmoplegia and panhypopituitarism, which were all manifested in our patient. $^{46}$

Another unique aspect of our case is the presence of bilateral ptosis and complete ophthalmoplegia with frozen globe. This occurred due to invasion of both cavernous sinuses and compression of cranial nerves III, IV and VI bilaterally, the extent of which has not been previously reported. ${ }^{9-12} 16$ Moreover, the tumour had also invaded the clivus and sphenoid sinus. Similar clivus involvement has been reported before with HCC but not together with ophthalmoplegia and panhypopituitarism. ${ }^{10} 11$ Interestingly, his optic nerve was intact bilaterally, which was reported in some cases. ${ }^{8}$

\begin{tabular}{llllll}
\hline \multicolumn{7}{l}{ Table 1} & \multicolumn{5}{l}{ Endocrine workup } \\
\hline LH & FSH & Prolactin & AM cortisol & TSH & Free T4 \\
\hline$<1$ & 1 & 3.64 & 2.7 & 0.022 & 0.4 \\
\hline
\end{tabular}

FSH, follicle-stimulating hormone; $\mathrm{LH}$, luteinising hormone; $\mathrm{TSH}$, thyroid-stimulating hormone. 


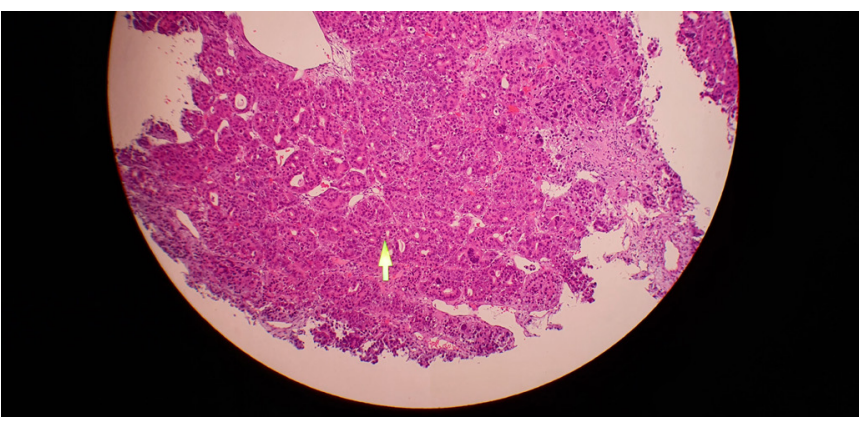

Figure 4 CT-guided core biopsy of the liver: cells showing pseudoglandular pattern consistent with hepatocellular carcinoma.

Panhypopituitarism is an important manifestation from pituitary metastases, and having a high index of suspicion for early detection is key. Secondary hypothyroidism and adrenal insufficiency are important sequelae that can lead to rapid mortality from hypovolemic shock if not recognised and addressed early. ${ }^{7}$ Neuropsychiatric manifestations in the form of alteration in mentation, delusions and hallucinations have also been described in some cases, ${ }^{17}{ }^{18}$ as was also noted in our case. Studies have shown that pituitary hormones, particularly cortisol and thyroxine, have a dominant effect on neurotransmitters of the brain such as serotonin, dopamine and gamma aminobutyric acid, and repleting them can reverse neuropsychiatric disturbances observed. ${ }^{17-19}$ Our case illustrates successful management of the life-threatening complication of pituitary metastasis given prompt recognition and early replacement of hormones with dexamethasone and levothyroxine.

Several options exist for the treatment of pituitary metastasis, including surgical resection, radiosurgery, radiation and chemotherapy. Increased vascularity and invasion of the cavernous sinus usually make surgical resection challenging, as in our case. ${ }^{15}$ Although palliative radiation is a viable option and the least invasive approach, it may not yield an adequate response with reversal of symptoms, as illustrated in our case. Despite prompt recognition of complications, mortality rate is high in pituitary involvement with average survival at 13.6 months. ${ }^{15}$

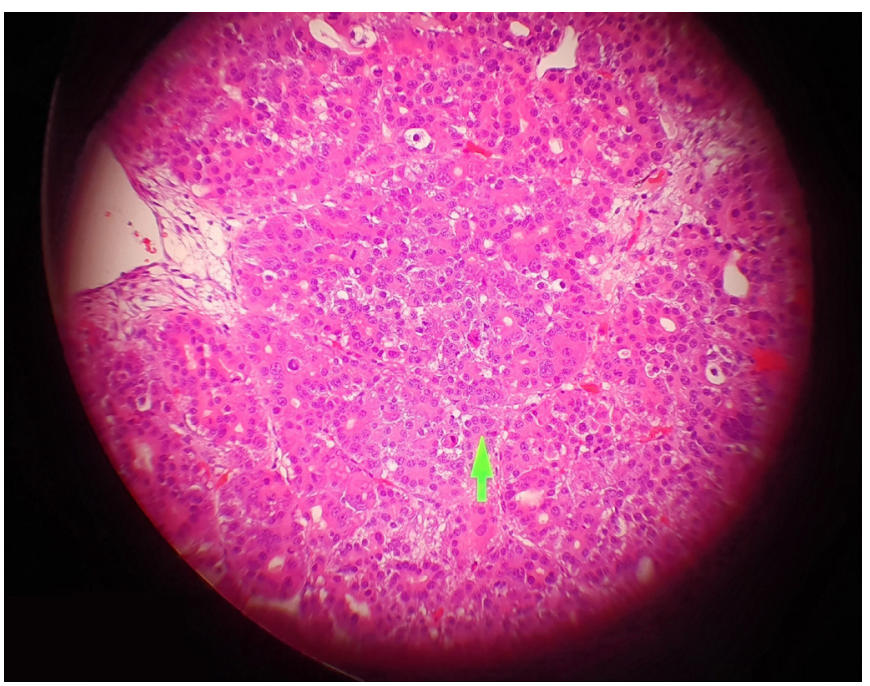

Figure 5 CT-guided core biopsy of the liver (high-power view): cells showing pseudoglandular pattern consistent with hepatocellular carcinoma.

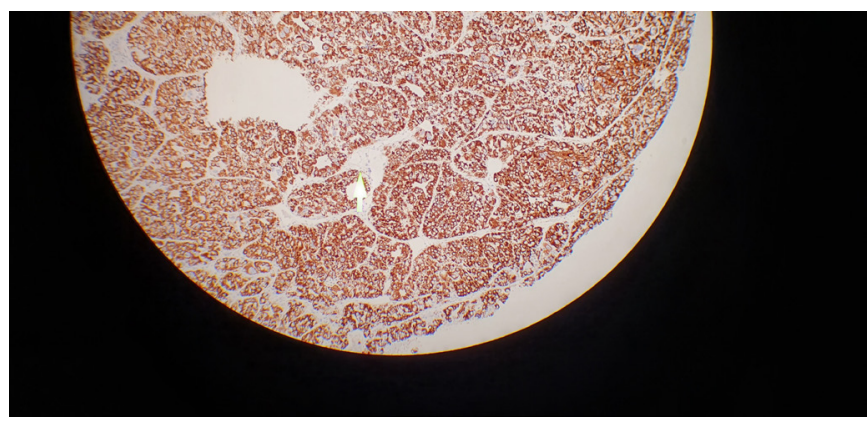

Figure 6 Posterior sphenoid sinus: transsphenoidal biopsy specimen-moderately differentiated carcinoma favours metastasis. The tumour cells are strong and diffusely positive for Hepar-1; show cytoplasmic staining for TTF-1; are focally positive for AE1/AE3, CK7 and CK5/6; and are negative for PSA, p63, CK20 and Cdx-2. This immunoprofile is compatible with hepatocellular carcinoma.

Metastases from HCC lead to an even lower survival, as in our case.

Unfortunately, our patient succumbed to his disease 2 weeks following his discharge, proving the aggressive nature of the disease.

\section{Learning points}

- Pituitary metastasis from hepatocellular carcinoma is an extremely rare and life-threatening complication.

- Clinicians must be aware of the symptoms of anterior pituitary metastasis and should not delay imaging of the brain.

- Extension of invasive tumour into the sphenoid and cavernous sinuses causes significant morbidity, as illustrated in our case.

- We present this unique case to underscore the importance of early recognition of panhypopituitarism in suspected cases of pituitary metastases.

- Replacement of hormones in a timely manner is essential in preventing haemodynamic compromise and subsequent mortality.

Acknowledgements We would like to acknowledge all the assistance offered by the pathologist and neuroradiologist for helping us with the histopathology slides and suitable imaging, respectively. We also like to thank our colleagues and attending physicians for guiding us throughout this process. Finally, we thank the patient himself for allowing us to learn from him.

Contributors JA was a part of the primary team taking care of the patient whose initial presentation was both unique and challenging clinically. MP and DJP were part of the oncology team who were consulted for the appropriate management of hepatocellular carcinoma. They were the ones who came with the idea for the case report and collaborated with the primary team for the report. The initial draft was made by JA who also made efforts to collect patient consent, clinical data, imaging and histopathological slides. After multiple edits and review by the oncology team, this manuscript is being submitted for review. We would also like to acknowledge the patient himself for consenting to publish his clinical data. In his words: "I would really want the medical community to learn more from patients like myself so that they can identify this disease early and treat appropriately"! We are extremely grateful to him.

Funding The Open Access cost of this publication was paid for by Medstar Health's GME department.

Competing interests None declared.

Patient consent for publication Obtained.

Provenance and peer review Not commissioned; externally peer reviewed. 
Open access This is an open access article distributed in accordance with the Creative Commons Attribution Non Commercial (CC BY-NC 4.0) license, which permits others to distribute, remix, adapt, build upon this work non-commercially, and license their derivative works on different terms, provided the original work is properly cited and the use is non-commercial. See: http://creativecommons.org/ licenses/by-nc/4.0/.

\section{ORCID iD}

Jayachidambaram Ambalavanan http://orcid.org/0000-0001-6923-8728

\section{REFERENCES}

1 Freda PU, Post KD. Differential diagnosis of sellar masses. Endocrinol Metab Clin North Am 1999;28:81-117.

2 Gsponer J, de TN, Déruaz J-P, et al. Diagnosis, treatment, and outcome of pituitary tumors and other abnormal intrasellar masses. Pdf Med 1999;78:236-69.

3 Schubiger 0 , Haller D. Metastases to the pituitary--hypothalamic axis. An MR study of 7 symptomatic patients. Neuroradiology 1992;34:131-4.

4 Morita A, Meyer FB, Laws ER. Symptomatic pituitary metastases. J Neurosurg 1998;89:69-73.

5 Abbas A, Medvedev S, Shores N, et al. Epidemiology of metastatic hepatocellular carcinoma, a nationwide perspective. Dig Dis Sci 2014;59:2813-20.

6 Fassett DR, Couldwell WT. Metastases to the pituitary gland. Neurosurg Focus 2004;16:1-4

7 Tanaka T, Hiramatsu K, Nosaka T, et al. Pituitary metastasis of hepatocellular carcinoma presenting with panhypopituitarism: a case report. BMC Cancer 2015;15:13-16.

8 Karamouzis MV, Melachrinou M, Fratzoglou M, et al. Hepatocellular carcinoma metastasis in the pituitary gland: case report and review of the literature. J Neurooncol 2003;63:173-7.
9 Tamura T, Kawamura Y, Ikeda K, et al. Hepatocellular carcinoma metastasis to the brain mimicking primary pituitary tumor around the sella turcica. Clin I Gastroenterol 2013:6:319-25.

10 Shah N, Cavanagh Y, Shaaban H, et al. An unusual initial presentation of hepatocellular carcinoma as a sellar mass. J Nat Sci Biol Med 2015;6:471-4.

11 Mishima H, Ayabe J, Watanabe M, et al. Clival metastasis of hepatocellular carcinoma with an initial histopathological diagnosis of atypical pituitary adenoma. J Neurol Surg Rep 2019;80:e18-22.

12 Komninos J, Vlassopoulou V, Protopapa D, et al. Tumors metastatic to the pituitary gland: case report and literature review. J Clin Endocrinol Metab 2004;89:574-80.

13 Aung TH, Po YC, Wong WK. Hepatocellular carcinoma with metastasis to the skull base, pituitary gland, sphenoid sinus, and cavernous sinus. Hong Kong Med J 2002;8:48-51.

14 Larocca G, Mattogno PP, Pompucci A, et al. An extremely rare case of a single isolated pituitary metastasis from hepatocellular carcinoma. vol. 61, Journal of neurosurgical sciences. Edizioni Minerva Medica 2017:213-5.

15 Javanbakht A, D'Apuzzo M, Badie B, et al. Pituitary metastasis: a rare condition. Endocr Connect 2018;7:1049-57.

16 Chakrabarti A. Isolated metastatic hepatocellular carcinoma masquerading as a pituitary Macroadenoma- a case report and review of literature. Gastroenterol Hepatol 2016;5:3-6.

17 Chang Y-C, Tsai J-C, Tseng F-Y. Neuropsychiatric disturbances and hypopituitarism after traumatic brain injury in an elderly man. J Formos Med Assoc 2006:105:172-6.

18 Ratnakaran B, Punnoose VP, Das S, et al. Psychosis in secondary empty sella syndrome following a Russell's viper bite. Indian J Psychol Med 2016;38:254-6.

19 Jegede 0 , Jeyakumar A, Balakumar T, et al. Neuropsychiatric manifestations in a patient with panhypopituitarism. Case Rep Psychiatry 2017;2017:1-3.

Copyright 2020 BMJ Publishing Group. All rights reserved. For permission to reuse any of this content visit

https://www.bmj.com/company/products-services/rights-and-licensing/permissions/

BMJ Case Report Fellows may re-use this article for personal use and teaching without any further permission.

Become a Fellow of BMJ Case Reports today and you can:

- Submit as many cases as you like

- Enjoy fast sympathetic peer review and rapid publication of accepted articles

- Access all the published articles

Re-use any of the published material for personal use and teaching without further permission

Customer Service

If you have any further queries about your subscription, please contact our customer services team on +44 (0) 2071111105 or via email at support@bmj.com. Visit casereports.bmj.com for more articles like this and to become a Fellow 